\title{
Biostimulants, soil improvers, bioprotectants: promoters of bio-intensification in plant production
}

\author{
Report on the 10th Symposium Plant Protection and Plant Health International jointly organized \\ by Deutsche Phytomedizinische Gesellschaft e.V. (DPG), Julius Kühn-Institut (JKI), and \\ University of Hohenheim -23rd November, Video Conference
}

Falko Feldmann ${ }^{1,2} \cdot J^{\prime}$ ohannes Jehle ${ }^{2} \cdot$ Klára Bradáčová $^{3} \cdot$ Markus Weinmann $^{3}$

Received: 3 December 2021 / Accepted: 3 January 2022 / Published online: 19 January 2022

(c) The Author(s) 2022

\begin{abstract}
The paper summarizes, after defining the meaning and agreed-upon usage of crucial key-concepts, the different perspectives of participants of the 10th Symposium Plant Protection and Plant Health International held on 23rd November 2021 on "Biostimulants, soil improvers, bioprotectants: promoters of bio-intensification in plant production" and the state of the art in the research on this topic. In total, 254 participants from 24 countries from around the world participated in the symposium, representing regulatory bodies, universities, federal research institutions, non-governmental associations, industry, advisors for plant protection, and practitioners of modern agricultural approaches. The results of presentations, discussions and post-symposium reactions are reported in this article.
\end{abstract}

Keywords Biostimulants $\cdot$ Soil improvers $\cdot$ Bioprotectants $\cdot$ Bio-intensification

\section{The symposium topic}

Production systems are considered as "sustainable" if input provides stable output with a minimum of unfavourable side effects to the environment. Many current plant production systems are characterized by fast growing, highly extractive plant varieties creating imbalanced ecological interrelationships. The respective inputs are mostly of chemical-synthetic nature, including mineral fertilizers, plant protection products, growth regulators etc., because they can be handled rather efficiently with predictable success and partially

Falko Feldmann

Feldmann@phytomedizin.org

1 Deutsche Phytomedizinische Gesellschaft E.V. (German Society for Plant Protection and Plant Health R.S., DPG), Messeweg 11-12, 38104 Brunswick, Germany

2 Julius Kühn-Institut, Federal Research Centre for Cultivated Plants, Erwin-Baur-Str. 27, 06484 Quedlinburg, Germany

3 Institute for Crop Science $(340 \mathrm{H}+\mathrm{I})$, Universität Hohenheim, Fruwirthstraße 20, 70599 Stuttgart, Germany replace or complement natural adaptations for nutrient acquisition and stress resilience.

However, the current view on modern agriculture is changing: integrated plant production means intensification in the use of natural components in plant production systems. Due to environmental issues, the use of chemicalsynthetical components should be minimized. In this context, establishing a more holistic, agro-ecological approach is necessary (Feldmann and Vogler 2020). The transformation process from the current conventional to more sustainable, future-oriented production systems is essential: Which strategies are the most promising? Do we need marketed (i.e. commercial) agents for a bio-intensification of our production system? Are all necessary components legally authorised for the producers?

Accordingly, this symposium dealt with three major questions: Can we find management options to re-establish natural cycles, thus helping us to equilibrate the system during production? How can soil improvers, biostimulants, and bioprotectants help to promote and boost bio-intensification? How is the current regulatory situation of biostimulants and bioprotectants? 


\section{Definitions}

The participants agreed to use the following definitions throughout the symposium:

Bio-intensification: the concept of bio-intensification aims to achieve adequate yields from a minimum area of farm land by increasing and sustaining biodiversity and soil fertility. A bio-intensified production system should be characterised by sustainability and closed nutrient cycles. Ideally, an effective balance of pests and beneficial organisms in an agro-ecological context should reduce input costs and make the approach economically viable. Management interventions in the bio-intensified production system should follow integrated plant management strategies and, if necessary, utilize biostimulants and bioprotectants rather than agro-chemicals for plant nutrition and plant protection, respectively. Especially during the transformation process from conventional to bio-intensified production, soil improvers and other biological agents can play an important role to start useful biological soil processes.

Biostimulants: According to Regulation (EU) 2019/1009, Article 47, a "plant biostimulant means a product stimulating plant nutrition processes independently of the product's nutrient content with the sole aim of improving one or more of the following characteristics of the plant or the plant rhizosphere: (a) nutrient use efficiency; (b) tolerance to abiotic stress; (c) quality traits; (d) availability of confined nutrients in soil or rhizosphere." (EU 2019). An overview is available in Rouphael and Colla (2020).

Soil improvers: According to Regulation (EU) 2019/1009, PFC 3, "a soil improver shall be an EU fertilising product the function of which is to maintain, improve or protect the physical or chemical properties, the structure or the biological activity of the soil to which it is added." (EU 2019).

Bioprotectants: The expression summarizes biocontrol agents of different areas of law (IBMA 2018): macro-organisms (used under national regulations in the EU), microorganisms (Regulations (EC) 1107/2009 and (EU) 2019/1009), botanicals and semio-chemicals (Regulation 1107/2009).

\section{Results}

\section{Agro-ecology as basis for bio-intensification}

Increasing biodiversity in agro-ecosystems induces and enhances bio-intensification processes. Miguel Altieri ${ }^{1}$ showed in his presentation how monocultural systems were

\footnotetext{
${ }^{1}$ University of California, Berkeley (UCB), Department of Environmental Science, Policy, and Management, USA; agroeco3@berkeley. edu.
}

(and in the future could be) transformed into cropping systems with higher biodiversity, revealing higher sustainability after transformation. Application of agro-ecological principles led to optimal crop diversification schemes (Nicholls and Altieri 2016). This crop diversification boosted interactions among biodiversity components essential for triggering key ecological processes such as soil ecological activation and pest regulation (Singh and Srinivas 2016).

Paul Mäder ${ }^{2}$ focussed in more detail on microbial biostimulants, which he called "biofertilizers": bacterial inoculants, such as Rhizobium, Azospirillum, Azotobacter and mycorrhizal fungi. The different types of biofertilizers are a viable option to make farming systems more sustainable, as he pointed out. Biofertilizers were found to be highly efficient at locations with initially low yields, under dry and tropical climate, with low soil organic carbon (SOC), moderate available $\mathrm{P}$ in soil, and neutral to slightly alkaline soil $\mathrm{pH}$. Effects are crop dependent: there is a high potential in transplanted crops (García-Fraile et al. 2015; Mäder et al. 2011; Schütz et al. 2017).

Rodrigo Mendes ${ }^{3}$ dedicated his research to Cook et al. (1995) who stated: "The defense strategy favored by selection pressure imposed on plants by soil borne pathogens may well be the ability of plants to support and respond to rhizosphere microorganisms antagonistic to these pathogens". This visionary citation led to intensive studies of microorganisms in the rhizosphere of host plants and resulted in an enhanced understanding of mechanisms how the rhizosphere and endosphere of plants act as first and secondly followed by microbiological layers of plant defence reactions. He showed that the rhizosphere microbiome could contain disease-suppressive bacteria which could be transferred to other sites to create disease suppressiveness of inoculated soils (Mendes et al. 2011). His group postulated that invading pathogenic fungi induces-directly or via plant—stress responses in the rhizobacterial community that lead to shifts in microbiome composition and to the activation of antagonistic traits that restrict pathogen infection (Chapelle et al. 2016). This hypothesis was later proven, and pathogeninduced activation of disease-suppressive functions in the endophytic root microbiome was demonstrated (Carrión et al. 2019).

On the background of agro-ecological observations on the field scale, the detailed analyses of Mäder and Mendes made clear that the complex interactions between microorganisms and host plants might be of major importance for plant health at a certain production site. At the same time, soil management measures including microbiome diversification may result in desired changes in the production system.

\footnotetext{
${ }^{2}$ FIBL, Switzerland; paul.maeder@ fibl.org.

3 EMBRAPA, Brazil; rodrigo.mendes@embrapa.br.
} 


\section{Bio-products for bio-intensification of production systems}

Worldwide, the assessment of biostimulants, soil improvers and bioprotectants should be harmonized to identify inherent product risks and to make products' efficacy more transparent (Caradonia et al. 2019; FAO 2017, 2019). In the $\mathrm{EU}$, for instance, the placing of plant protection products on the market is regulated for all member states since 2011 (EU, 2009). While the regulation of pesticides has widely been harmonized years ago, the regulation 2019/1009 for fertilizers and biostimulants enters into force in 2021. Placing biostimulant products on the EU market actually poses scientific and regulatory challenges.

Patrick du Jardin ${ }^{4}$ pointed out that according to fertilizer regulation (EU) 2019/1009, biostimulant products are defined by "claims", i.e. by their agricultural functions, not by their composition and not by their modes of action. During the regulation process, a verification of compliance of marketed product categories to relevant legal provisions covered by fertilizer regulations takes place. Plant protection products instead are authorized case by case by a costintensive process first on the level of active substances and second as formulated product. Because biostimulants may contain microorganisms which at the same time have some biocontrol activity, the regulation (EU) 2019/1009 states: "Products with one or more functions, one of which is covered by the scope of Regulation (EC) No 1107/2009, are plant protection products falling within the scope of that Regulation. Those products should remain under the control developed for such products and provided for by that Regulation” (EU 2019). Patrick du Jardin highlighted that the key for understanding of the distinction between biostimulation and plant protection is that the "function" is more than an "effect".

Functionality would be defined as "capacity of a product to fulfil some desired function under specified conditions of use", while effectiveness would be the "intrinsic capacity of a substance or microorganism to affect any recipient organism".

Avenues for including new microorganisms into the currently very limited list of microbial plant biostimulants are identified, but satisfying criteria bearing on both biology and trade need to be found.

Christina Donat ${ }^{5}$ stated that in spite of high registration costs, the market of bioprotectants has been growing for years. Small and midsize enterprises (SMEs) are the main drivers of development and marketing of bioprotectants in Europe; according to respondents of an IBMA survey,

\footnotetext{
${ }^{4}$ University of Liège, Belgium; patrick.dujardin@uliege.be.

5 IBMA, Austria; c.donat@e-nema.de.
}

approximately $61 \%$ (313 Million Euros) of sales in this category were generated by SMEs. More than 1600 biocontrol products are available across different European member states, and $87 \%$ of these products originate from SMEs. In spring 2021, more than 104 products were in the authorisation process pipeline across Europe, and an additional 102 products had not yet been submitted to the authorisation process. Active ingredient submissions by members are also numerous. There are two drivers in the market: for one political decisions supporting the use of bioprotectants by further restricting the use of chemical-synthetical pesticides, and secondly the demand of consumers for organic and integratedly produced crops, both leading to the use of biointensified methods of plant protection and of biostimulants in their production (IBMA 2021).

Ilaria Pertot ${ }^{6}$ discussed the question of how botanicals can be developed into sustainable biofungicides. She figured out that botanicals have to show characteristics similar to chemical-synthetical fungicides: sufficient efficacy under field conditions, technical feasibility (scalability, industrial production, sufficient raw plant material, etc.), economic feasibility (cost/benefit, competitors, etc.), feasibility of authorization under (EU) regulations (side effects, human and environmental toxicity, shelf-life, etc.). These criteria have to fulfil the requirements of the regulations EU 283/2013 and 284/2013 (EU 2013a, b). Because of the extremely heterogeneous nature of botanicals, ranging from simple plant powders to unprocessed and processed plant extracts, specific requirements exist as laid down in document SANCO/11470/2012- rev. 8, 20 March 2014 (Sanco 2017). According to Article 23 of regulation 1107/2009 (EU 2009), some plant extracts can also be placed on the market as so-called basic substances. Basic substances are approved as active substances with much less data requirements (Feldmann and Carstensen 2018). Traditional home-made preparations, which are not only used in non-professional gardens, but also in organic agriculture (Demeter 2019) are not assessed, and often bear risks, which should be communicated to users when discovered during the assessment process of, e.g. basic substances (Sanco 2021).

The importance of beneficial arthropods in crop management was outlined by Annette Herz. ${ }^{7}$ Insects serving as pollinators, predators, and parasitoids are essential for sustainable crop management. Therefore, insect decline is a risk for sustainable crop management. It leads to the loss of predatory or parasitic "natural enemies" of pests (Gatter et al. 2020). The EU nature restoration plan declares that by 2030 , the risk and use of chemical pesticides shall be reduced by $50 \%$ that at least $10 \%$ of agricultural areas shall

\footnotetext{
${ }^{6}$ University of Trento, Italy; ilaria.pertot@ fmach.it.

7 Julius Kühn-Institut, Germany; annette.herz@julius-kuehn.de.
} 
be high-diversity landscapes, and that at least $25 \%$ of agricultural land shall be under organic farming management, including a significant increase in agro-ecological practices. These aims require an increase in natural resources for beneficials and of habitat diversification, e.g. by implementing tailored companion plants and flower strips (Cahenzli et al. 2019), by implementing ecological infrastructures (Jamar 2019), and by crop diversification (Gurr et al. 2016). Another option to boost arthropods is the intensification of specific biotic interactions, i.e. the augmentative release of key natural enemies and the introduction of exotic natural enemies (van Lanteren 2012). In the EU, regulations for the use of beneficial organisms still need to be harmonized, just like risk assessment procedures when exotic beneficials are introduced.

\section{Bio-intensification of cropping systems}

José Pereira da Silva Júnior ${ }^{8}$ gave an example of bio-intensification in the industrial agriculture of South Brazil. Tropical soils are normally chemically poor but bear a high potential of biological and microbiological diversity and activity. Their ecological interactions are complex and intensive. Primary production is very dependent on nutrient recycling and nutrient input. In fact, huge amounts of chemical fertilizers have to be used for sufficient yields and are of high costs. Brazil, therefore, turned already very early to the use of microorganisms for different functions and enhanced the microbial effectiveness by appropriate management. Microorganisms are used as biocontrol agents, growth promoters, and biofertilizers at an industrial scale. Because of the drastic impact, the inoculant market in Brazil is steadily increasing. Inoculants are registered at strain level, and each strain is deposited in an authorized depository (Moraes and Azevedo 2016). With the given examples provided by Pereira da Silva Junior, it became clear that microorganisms can effectively substitute chemical fertilizers. A diversification of monocultures is not intended in Brazil, because of competition relationships on the world market.

Borbala Biro 9 outlined the Hungarian strategy to increase the percentage of organic agriculture by demonstrating practitioners the potential of microbial inoculant usage in horticulture for improving the soil health. For one, biostimulants' effects were shown under practical conditions in the field, and secondly under small-scale horticultural conditions. Parallel, scientific studies accompanied these demonstration experiments and highlighted interactions between microbial inocula, fertilization, pesticide use, and plant genotypes in

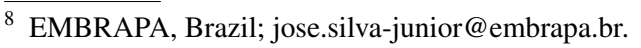

9 Hungarian University of Agriculture and Life Sciences, Hungary; biro.borbala@gmail.com.
}

managed soils. As a consequence, a "soil health concept is proclaimed, which takes the importance of especially symbionts in the soil into account. She recommended, to qualify professional "soil health doctors" to communicate not only the importance of the condition of soils but also to integrate soil health into good agricultural practice.

Ecosystem services in permaculture systems were presented by Sarah Hirschfeld. ${ }^{10}$ She introduced ecosystem services with the quotation "Agriculture is applied Ecology" (Jackson and Piper 1989). She divided ecosystem services into supporting services, regulating services, provisioning services and "disservices" (Kragt and Robertson (2014). Bio-intensification following the permaculture concept is favouring the establishment of these different ecosystem services (Ferguson and Lovell 2014, 2017). One of the most important measures is that perennial crop species are strategically integrated into agricultural landscapes (perennialization). Multiple crop species or cultivars are grown concurrently in the same location (crop diversification). Furthermore, a zone design landscape (matrices \& nature sparing) is applied. On-site natural or semi-natural areas are protected or restored from cropping activities, thus permitting wild species to grow (nature sparing). Once developed, the sum of all activities creates more than the parts: sustainability and resilience to disturbances (Hirschfeld and van Acker 2020, 2021).

\section{Conclusive statement}

An intensive discussion of the presentations followed each presentation and at the end of the symposium and continued even after the symposium, leading to further statements summarizing necessary requirements and conditions, prerequisites, and tools for bio-intensification in future plant production systems.

Agro-ecological thinking is the pre-requisite for future-oriented production system designs Production systems might be very different in structure or use intensity. The decisive ecological components of bio-intensified production, though, are the same everywhere with agro-ecological thinking opening the eyes to analyse the core elements for the actual situation at different sites. The size of fields, the spatial distance to surroundings, the type of ecosystem in the vicinity of the field, the mode of technical facilities used, or treatments related to the production-all these criteria induce a variability of ecosystem services. It seems to be obvious that with a higher state of biodiversity in a production system, a higher number of influential ecosystem

\footnotetext{
$\overline{{ }^{10} \text { University }}$ of Guelph, Canada; sarah.e.hirschfeld@ gmail.com.
} 
services can be expected. All factors have to be taken into account to reach sustainable plant production.

As a consequence, large-scale monocultures should be turned into more diverse production systems.

In a future-oriented production system, the cultivated plant is embedded into interaction networks of abiotic and biotic factors Microbial symbionts are of major importance for positive, mutualistic effects, but as well for detrimental effects leading to plant damage and yield loss. The goal of bio-intensification is to manage growing conditions in such a way that they do not support the settlement of plant diseases and plant pests, but rather of microbial (and macrobial) communities in the plant rhizosphere and endosphere that suppress such harmful organisms.

Bio-intensification is supported by industrial companies that place larger numbers of new products on the market, including microbial and non-microbial biostimulants, biopesticides, basic substances, and beneficial macroorganisms. Botanicals are also used as non-marketed selfproduced-preparations (home-made pesticides).

Legislation procedures need to be harmonized worldwide: currently, the legislation procedure of the different products follows different legal regulations worldwide and is very differently interpreted. The criteria of risk and efficacy assessment show a large variability worldwide, and no clear and consistent classification exists around the world.

Home-made preparations are recommended by the FAO, but do not undergo a risk assessment process. In Europe, information about unwanted side effects found in basic substance assessments is not extrapolated to self-produced-preparations.

Production systems can be further improved by using naturally occurring or artificially introduced macroand microorganisms or non-microbial biostimulants. If the natural basis is diverse and stable, the modification of agricultural cultivation methods can be the key for starting a change to more ecologically equilibrated production systems. Introducing microorganisms to production systems can boost the system only for a short time, e.g. one season, if the microbes cannot establish sustainably. Sustainable establishment of microorganisms is only possible, if the growth conditions for them are appropriately modified in the production system parallel to inoculation. Modifications of the abiotic environment can be effectively initiated by non-microbial biostimulants and soil improvers, which nevertheless might have positive or negative effects on other soil factors.

Creation of habitats for beneficials can lead to an establishment of these biocontrol agents for both, shortterm and long-term usage. New designs like fragmented fields with high biodiversity or traditional permaculture design may support the transformation of agricultural systems. Similarly, concepts of spot farming may increase the crop diversity and a better-adjusted consideration of abiotic and biotic local factors.

Bio-products like biostimulants and soil improvers, botanicals or microbial pesticides cannot completely substitute agro-chemicals in industrial agriculture and nor in horticulture without changing the production system. In industrial agriculture, the use of biofertilizers may substitute agro-chemicals partially. Similar to them, biostimulants have to be applied every year again. The biostimulant price regulates the bio-intensification performance. As shown in this case of monoculture based, glyphosate-resistant transgenic soybean production, biostimulants can even successfully support highly non-sustainable production systems like demonstrated here for Brazil and Argentina.

Regulations of bio-products should be developed together with scientists who are specialists in the specific field. Even though this currently is the case already very often, the outcome of scientific hearings is often less recognized than the requests of lobby organizations, including political organizations; this leads to unsatisfying situations for farmers, consumers and industry.

Important stakeholders of bio-intensification projects, e.g. organic growers, should not only be treated as users of bio-products, but as developmental partners for industrial companies helping them to figure out how the transformation of conventional agriculture could succeed. Industry may function as a link between an agrochemical and a biointensified world.

Science should turn to analyse highly complex production systems and should demonstrate input/output relations to find a science-based developmental approach for future agricultural systems.

Stakeholders of highly diverse production systems should recognize that input/output relations are very important measures to convince conventional, industrial agricultural producers to change. They should speak openly about their successes and their failures and provide insight into the ecosystem services they use. What is needed urgently is a platform for an approachment of industrial producers on the one side and bio-intensified agricultural ones on the other, which offers the chance for a merger of ecological thinking and mechanization and digitalisation-or, to express it even more bluntly, a turn to a new and sustainable agriculture based on ecology that nevertheless produces yields that satisfy the world's demands for sufficient food and food security.

In summary, the symposium on "Biostimulants, soil improvers, bioprotectants: promoters of bio-intensification in plant production" can be seen as a very effective and fruitful event, because discussions between members of different stakeholder groups revealed new insights to all participants, and important aspects to be considered in the transformation 
of agriculture towards sustainable and resilient plant production systems were highlighted.

All presentations are available at the symposium website www.plant-protection.net/de/ppphi/.

Acknowledgements We would like to thank the Programme Committee for the important inputs in the design of an attractive programme with excellent speakers on a future-oriented topic: Manfred Raupp, Biofector Project, Madora, Lörrach, Germany; Günter D. Neumann, BONARES-Projekt DiControl, University of Hohenheim, Hohenheim, Germany; Ewa Matyjaszczyk, European Plant Protection Organisation (EPPO), Paris, France. Martin Kulhánek, Czech University of Life Sciences, Prague, Czech Republic; Ciprian George Fora, Banat`s University of Agricultural Sciences and Veterinary Medicine "King Michael I of Romania", Romania; José Pereira Silva Junior, EMBRAPA, Passo Fundo, Brazil.

Funding Open Access funding enabled and organized by Projekt DEAL.

\section{Declarations}

Conflict of interest The authors declare that they disclose financial or non-financial interests that are directly or indirectly related to the work submitted for publication.

Open Access This article is licensed under a Creative Commons Attribution 4.0 International License, which permits use, sharing, adaptation, distribution and reproduction in any medium or format, as long as you give appropriate credit to the original author(s) and the source, provide a link to the Creative Commons licence, and indicate if changes were made. The images or other third party material in this article are included in the article's Creative Commons licence, unless indicated otherwise in a credit line to the material. If material is not included in the article's Creative Commons licence and your intended use is not permitted by statutory regulation or exceeds the permitted use, you will need to obtain permission directly from the copyright holder. To view a copy of this licence, visit http://creativecommons.org/licenses/by/4.0/.

\section{References}

Cahenzli F, Sigsgaard L, Daniel C et al (2019) Perennial flower strips for pest control in organic apple orchards-a pan-European study. Agric Ecosyst Environ 278:43-53

Caradonia F, Battaglia V, Righi L, Pascali G, La Torre A (2019) Plant biostimulant regulatory framework: prospects in Europe and current situation at international level. J Plant Growth Regul 38:438-448

Carrión VJ, Perez-Jaramillo J, Cordovez V et al (2019) Pathogeninduced activation of disease-suppressive functions in the endophytic root microbiome. Science 366:606-612

Chapelle E, Mendes R, Bakker PAHM, Raaijmakers JM (2016) Fungal invasion of the rhizosphere microbiome. ISME J 10:265-268

Cook RJ, Thomashow LS, Weller DM et al (1995) Molecular mechanisms of defense by rhizobacteria against root disease. Proc Natl Acad Sci USA 92:4197-4201

Demeter EV (2019) Steiners impulse. https://www.demeter.de/sites/ default/files/public/pdf/steiners_impulse_demeter_biodynamisch. pdf. Accessed 3 Nov 2021
EU (2009) Regulation (EC) No 1107/2009 of the European Parliament and of the Council of 21 October 2009 concerning the placing of plant protection products on the market and repealing Council Directives 79/117/EEC and 91/414/EEC

EU (2013a) Commission regulation (EU) No 283/2013 of 1 March 2013 setting out the data requirements for active substances, in accordance with Regulation (EC) No 1107/2009 of the European Parliament and of the Council concerning the placing of plant protection products on the marketText with EEA relevance

EU (2013b) Commission regulation (EU) No 284/2013 of 1 March 2013 setting out the data requirements for plant protection products, in accordance with Regulation (EC) No 1107/2009 of the European Parliament and of the Council concerning the placing of plant protection products on the marketText with EEA relevance

EU (2019) Regulation (EU) 2019/1009 of the European Parliament and of the Council of 5 June 2019 laying down rules on the making available on the market of EU fertilising products and amending Regulations (EC) No 1069/2009 and (EC) No $1107 / 2009$ and repealing Regulation (EC) No 2003/2003

FAO (2017) International code of conduct on pesticide management. In: Guidelines for the registration of microbial, botanical and semiochemical pest control agents for plant protection and public health uses. FAO

FAO (2019) Registration toolkit. https://www.fao.org/pesticide-regis tration-toolkit/en/. Accessed 24 Nov 2021

Feldmann F, Carstensen C (2018) Efficacy and risks of "biorationals." J Plant Dis Prot 125:517-521

Feldmann F, Vogler U (2020) Towards sustainable performance of urban horticulture: ten challenging fields of action for modern integrated pest management in cities. J Plant Dis Prot 128:1-12

Ferguson RS, Lovell ST (2014) Permaculture for agroecology: design, movement, practice, and worldview: a review. Agron Sustain Dev 34:251-274

Ferguson RS, Lovell ST (2017) Livelihoods and production diversity on U.S. permaculture farms. Agroecol Sustain Food Syst 41:588-613

García-Fraile P, Menéndez E, Rivas R (2015) Role of bacterial biofertilizers in agriculture and forestry. AIMSBOA 2:183-205

Gatter W, Ebenhöh H, Kima R, Gatter W, Scherer F (2020) 50-jährige Untersuchungen an migrierenden Schwebfliegen, Waffenfliegen und Schlupfwespen belegen extreme Rückgänge (Diptera: Syrphidae, Stratiomyidae; Hymenoptera: Ichneumonidae). Entomol Z 130:131-142

Gurr GM, Lu Z, Zheng X et al (2016) Multi-country evidence that crop diversification promotes ecological intensification of agriculture. Nature Plants 2:16014

Hirschfeld S, van Acker R (2020) Permaculture farmers consistently cultivate perennials, crop diversity, landscape heterogeneity and nature conservation. Renew Agric Food Syst 35:342-351

Hirschfeld S, van Acker R (2021) Review: ecosystem services in permaculture systems. Agroecol Sustain Food Syst 45:794-816

IBMA (2018) IBMA white paper: new EU regulatory framework for Bioprotection agents IBMA. In: Vision on how to improve regulation in the European Union

IBMA (2021) IBMA Biocontrol success website. https://www.ibmab iocontrolsuccess.org/case/. Accessed 25 Nov 2021

Jackson W, Piper J (1989) The necessary marriage between ecology and agriculture. Ecology 70:1591-1593

Jamar L (2019) Perennial flower strips for pest control in organic apple orchards: a pan-European study. CRA-W

Kragt ME, Robertson MJ (2014) Quantifying ecosystem services trade-offs from agricultural practices. Ecol Econ 102:147-157

Mäder P, Kaiser F, Adholeya A et al (2011) Inoculation of root microorganisms for sustainable wheat-rice and wheat-black gram rotations in India. Soil Biol Biochem 43:609-619 
Mendes R, Kruijt M, de Bruijn I et al (2011) Deciphering the rhizosphere microbiome for disease-suppressive bacteria. Science 332:1097-1100

Moraes J, Azevedo P (2016) Biostimulants: identification of regulatory challenges and proposals to make this agri-input viable in Brazil. Acta Hortic 1148:101-104

Nicholls CI, Altieri MA (2016) Agroecology: principles for the conversion and redesign of farming systems. J Ecosyst Ecogr 01

Rouphael Y, Colla G (2020) Editorial: biostimulants in agriculture. Front Plant Sci 11:40

Sanco (2017) Guidance document on botanical active substances used in plant protection products. OECD

Sanco (2021) Working document on the procedure for application of basic substances to be approved in compliance with Article 23 of Regulation (EC) No 1107/2009 COMMISSION. SANCO/10363/2012 Rev.10; 25 January 2021
Schütz L, Gattinger A, Meier M et al (2017) Improving crop yield and nutrient use efficiency via biofertilization-a global meta-analysis. Front Plant Sci 8:2204

Singh HS, Srinivas P (2016) Concept of bio-intensification of orchard for pest management (BIOPM) in mango

van Lanteren JC (2012) IOBC internet book of Biological Controlversion 6

Publisher's Note Springer Nature remains neutral with regard to jurisdictional claims in published maps and institutional affiliations. 